\title{
A SUBVERSÃO PRINCIPIOLÓGICA NA EXECUÇÃO PENAL E O PRINCÍPIO NE BIS IN IDEM
}

THE SUBVERSION PRINCIPLED IN IMPRISONMENT
EXECUTION AND THE PRINCIPLE NE BIS IN IDEM

\author{
Klélia Canabrava Aleixo ${ }^{1}$ \\ PUC Minas \\ Flávia Ávila Penido² \\ PUC Minas
}

\section{Resumo}

O presente artigo visa analisar a aplicação do Princípio ne bis in idem à partir da análise de um acórdão do Tribunal de Justiça de Minas Gerais (n.10481.13.0050869/002) fundamentado na existência de um suposto “bis in idem contra o Estado". Tem como pano de fundo a estrita vinculação dos princípios à Constituição, notadamente a partir dos estudos do uruguaio Eduardo J. Couture, bem como a premissa de que os princípios, por sua natureza e colocação sistêmica, deveriam ser voltados à proteção do indivíduo. A hipótese de trabalho confirmada é a de que o princípio foi subvertido para estender arbitrariamente o exercício do poder punitivo do Estado. O procedimento metodológico utilizado foi o dedutivo com a realização de pesquisas bibliográfica, documental e jurisprudencial.

\section{Palavras-chave:}

Constituição. Princípios. Interpretação. Subversão. Execução Penal.

\footnotetext{
${ }^{1}$ Doutora em Políticas Públicas e Formação Humana pela Universidade do Estado do Rio de Janeiro. Mestra em Ciências Penais pela Universidade Federal de Minas Gerais. Professora do Programa de Pós-Graduação em Direito da Pontifícia Universidade Católica de Minas Gerais

2 Mestra em Direito Processual pela Pontifícia Universidade Católica de Minas Gerais. Especialista em Direito Público. Advogada.
} 


\section{Abstract}

The purpose of this article is to analyze the application of the ne bis in idem Principle, based on the analysis of a judgment of the Court of Justice of Minas Gerais and succeeded in substantiating the existence of a so-called "bis in idem against the State". This work has as a background the strict binding of the principles to the Constitution, especially from the studies of the Uruguayan Eduardo J. Couture, as well as the premise that the principles, by their nature and systemic placement, should serve at the protection of the individual. The working hypothesis is that the principle has been subverted to arbitrarily extend the exercise of the punitive power of the State. The methodological procedure used was the deductive one with the accomplishment of bibliographical, documentary and jurisprudential researches.

\section{Keywords:}

Constitution. Principled. Interpretation. Subversion. Penal execution.

Discursos que podem matar, discursos de verdade e discursos que fazem rir. E os discursos de verdade que fazem rir e que têm o poder institucional de matar são, no fim das contas, numa sociedade como a nossa, discursos que merecem um pouco de atenção. (FOUCAULT, 2002, P. 8)

\section{INTRODUÇÃO}

O presente artigo visa analisar a aplicação do princípio ne bis in idem no julgamento dos embargos infringentes e de nulidade número 1.0481.13.005086-9/002, com acórdão proferido pela 6 a Câmara Criminal do Tribunal de Justiça de Minas Gerais.

A hipótese de trabalho é a de que o princípio, que por sua natureza é voltado à proteção do indivíduo, foi subvertido para estender arbitrariamente o exercício do poder punitivo do Estado.

Para realizar a investigação passou-se a investigar a função dos princípios à partir de sua vinculação constitucional, como paradigma que deve nortear a interpretação e aplicação das leis. Pondera-se que 
as normas interpretativas são de índole sistêmico-operacional e, portanto, pertencem ao âmbito de reflexão do direito processual.

Considerando que a origem dos estudos acerca da constitucionalização do processo guarda profundas raízes em Eduardo Couture, elegeu-se neste ensaio os contributos do autor uruguaio como norteadores da compreensão da estrita relação dos princípios com a Constituição na formação do sistema jurídico.

Partindo desta estrita vinculação principiológica aos ditames constitucionais e da premissa de que os princípios constituem garantia aos sujeitos frente ao poder do Estado, buscou-se conhecer a origem, o significado e a natureza do princípio ne bis in idem.

Da compreensão de tais características pretende-se investigar a possibilidade de desvirtuamento na aplicação do referido princípio no julgado em análise, que negou recurso do condenado com base na fundamentação da existência de um suposto "bis in idem contra o Estado".

\section{O PLEXO ENTRE A CONSTITUIÇÃO E OS PRINCÍPIOS EM EDUARDO COUTURE}

Eduardo J. Couture foi pioneiro nos estudos que tratam do entrelaçamento entre o direito processual e a Constituição, oferecendo novo pano de fundo para o estudo da disciplina: a vinculação às garantias constitucionais. Não foi por outra razão que André Cordeiro Leal chegou a afirmar que o autor uruguaio foi um dos processualistas mais atentos para a questão das garantias constitucionais relativas ao processo. (LEAL, 2008, p.100)

A transcendência constitucional das instituições processuais proposta por Couture teve grande repercussão entre os juristas latinoamericanos e europeus impulsionando essa nova perspectiva da ciência 
processual (FIX-ZAMUDIO, 1998, p. 188-189), o que representou um significativo contributo ao desenvolvimento do direito processual na sua perspectiva democrática.

Considerando que a origem dos estudos acerca da constitucionalização do processo guarda profundas raízes em Eduardo Couture, elegeu-se neste ensaio os contributos do autor como norteadores da compreensão da estrita relação dos princípios com a Constituição. Pondera-se que as normas interpretativas são de índole sistêmico-operacional e, portanto, pertencem ao âmbito de reflexão do direito processual. Por tal motivo o autor uruguaio dedicou uma obra ${ }^{3}$ ao tema da interpretação, oportunidade em que tentou situar os princípios no ordenamento jurídico como decorrentes de mandamentos constitucionais maiores - no sentido de amplitude e generalidade de suas expressões.

O reconhecido contributo de Couture ao entrelaçamento entre o direito processual e a Constituição encontra síntese em sua obra editada em 1948, ${ }^{4}$ sem descuidar, contudo, da abordagem que o autor faz na obra "Interpretação das leis processuais", cuja primeira edição brasileira data de $1956 .{ }^{5}$ No primeiro livro, o autor informa que

${ }^{3}$ COUTURE, Eduardo J. Interpretação das leis processuais. Trad. Gilda Maciel Corrêa Meyer Russomano. 4. ed. Rio de Janeiro: Forense, 1994.

${ }_{4}$ COUTURE, Eduardo J. Estudios de derecho procesal civil: la constitución y el proceso civil. T.1. Buenos Aires: Ediar, Soc. Anón., Editores, 1948.

5 Trata-se da compilação das notas taquigráficas de um minicurso ministrado por Couture na Faculdade de Direito de Paris, em 1949, notas estas que foram originalmente publicadas na revista da faculdade no mesmo ano. Posteriormente o texto foi publicado no tomo III da 
pretende demonstrar em que medida as normas infraconstitucionais regulamentam a garantia de justiça contida na Constituição.(COUTURE, 1948, p. 19) Na segunda obra, Couture explica como se dá a transição do mandamento constitucional à norma processual, oportunidade em que trata da função dos princípios como intermediários entre a Constituição e as normas infraconstitucionais.

Segundo Couture, a Constituição foi redigida na forma de grandes mandamentos, no sentido de amplitude e generalidade de suas expressões. Protege genericamente a vida humana, como garantia fundamental, e delega ao legislador os pormenores desta proteção. (COUTURE, 1947, p. 517-518)

Dessa forma, a Constituição oferece uma primeira estrutura basilar da ordem jurídica, na forma de mandamentos constitucionais. Considerando a sua generalidade, apresenta "o mais vasto panorama de aplicação de um preceito adjetivo". (COUTURE, 1994, p.37)

Estes mandamentos constitucionais são desenvolvidos através dos princípios, como um "programa de ação", de forma que se deve estruturar a lei tendo como ponto de referência alguns destes princípios. Segundo o autor uruguaio "o sistema legal é, pois, um sistema de princípios que constituem uma espécie de esqueleto, a estrutura rígida e interna da obra, seu arcabouço lógico, sobre o qual se ordenam os detalhes da composição". (COUTURE, 1994, p.38-40)

Do exposto por Couture é possível compreender que há estrita relação entre o texto constitucional e os princípios, de forma que estes encontram seu fundamento último naquele.

obra Estudios de Derecho Procesal Civil, datada de 1950, nas páginas 15 a 65. 


\subsection{A VINCULAÇÃO DA INTERPRETAÇÃO AO CONTEÚDO ORIGINÁRIO DOS PRINCÍPIOS}

Esta visão dos princípios como resultado do desenvolvimento de um mandamento constitucional maior vincula a sua interpretação ao paradigma constitucional, de forma que "a atitude do operador jurídico deve ser comissiva, de interpretação e filtragem dos institutos jurídico-penais a partir do texto constitucional" visto que "a efetivação das garantias não cabe tão-somente ao poder político, mas fundamentalmente aos juristas, através do processo de (re) interpretação dos textos". (CARVALHO, 2008, p. 160)

Nesse sentido, na atividade interpretativa há que se prezar pela demarcação dos princípios como marco balizador de conceitos que tem na sua órbita imperativa (prescritiva) pressupostos que lhe são inferentes. Na interpretação destes pressupostos não se admite que haja flexibilização incompatível com o conteúdo principiológico que lhe deu causa. (LEAL, 2016, p. 166)

Considerando que a Constituição é enunciativa do Estado Democrático de Direito, é a partir dela que se pode interpretar e concretizar o discurso jurídico democrático. Portanto, ao empregar-se um princípio como balizador da interpretação, "tal não poderia ser contra-legem, porque, se o fosse, inaugurar-se-ia uma nova forma legiferante sobreposta ao ordenamento em vigor". O princípio então não pode ser cambiável quando assegura o entendimento de preceitos constitucionais como condição de legitimidade. (LEAL, 2005, p. 91-94)

Tendo em vista o pano de fundo constitucional que norteia os princípios, não se admite que a sua interpretação restrinja direitos salvaguardados pelo texto constitucional. Diante das possibilidades interpretativas, deve-se optar por aquela que mais atenta à salvaguarda 
dos direitos assegurados constitucionalmente, ampliando a proteção individual frente ao Estado.

Isso porque, especialmente em matéria penal, eles são concebidos como limitadores do potentia puniendi, carente de contenção e redução. (ZAFFARONI, 2003, p. 201) ${ }^{6}$ Sendo os princípios expressões dos direitos e garantias constitucionais, sua interpretação não pode ser realizada contra o indivíduo.

\section{O PRINCÍPIO NE BIS IN IDEM COMO GARANTIA CONSTITUCIONAL}

O princípio ne bis in idem dispõe que ninguém será processado ou punido por fato pelo qual já tenha sido absolvido ou condenado por sentença transitada em julgado. Em dissertação de Mestrado intitulada $\mathrm{Ne}$ bis in idem. Limites jurídico-constitucionais à persecução penal, defendida por Keity Saboya no Programa de Pós-Graduação em Direito da Universidade Federal do Rio Grande do Norte, a autora observa que a delimitação do momento exato do surgimento do referido princípio constitui tarefa impossível. (SABOYA, 2006, p. 131) Quanto a sua origem:

Para a grande maioria da doutrina, sua origem liga-se ao direito romano, tendo surgido como consequência lógica do instituto da coisa julgada, derivado do caráter preclusivo do processo, a partir da fase denominada litis contestatio, utilizada para solucionar eventual

${ }^{6}$ Conforme destacado por Zaffaroni o jus puniendi não existe, o que há é uma potentia puniendi que necessita de contenção e redução. ( ZAFFARONI, Eugênio Raúl et al. Direito penal brasileiro: teoria geral do direito penal. 2. ed. Rio de Janeiro: Revan, 2003, v. 1., p. 201). 
concorrência de ações. No entanto, alguns autores defendem que o princípio ne bis in idem originou-se no direito grego, na arte da Retórica dos Áticos. (SABOYA, 2006, p. 131$)^{7}$

No plano internacional, o ne bis in idem é reconhecido como um princípio geral de direito internacional, tendo o Pacto Internacional de Direitos Civis e Políticos outorgado o caráter de princípio universal, ao estabelecer em seu art. 14.7 que "ninguém poderá ser julgado ou punido novamente por um delito pelo qual já tenha sido absolvido ou condenado por sentença transitada em julgado, de acordo com a lei e o processo penal de cada país". (SABOYA, 2006, p. 134)

Encontra previsão também no art. 4º do Protocolo 7º, adicional ao Convênio de Direitos Humanos; no art. 50 da Carta dos Direitos Fundamentais da União Europeia; na Convenção de Aplicação do Acordo de Schengen; no art. 50 da Carta dos Direitos Fundamentais da União Europeia e no art. 8.4 da Convenção Americana sobre Direitos Humanos. (GIACOMOLLI, 2015, p.329-330)

O Brasil ratificou o Pacto Internacional dos Direitos Civis e Políticos e a Convenção Americana sobre Direitos Humanos (Pacto de São José da Costa Rica). Conforme disposto no art. $5^{\circ}$, $\S 2^{\circ}$ e $\S 3^{\circ}$ da Constituição Federal de 1988 (CF) os tratados e convenções internacionais sobre direitos humanos são equivalentes à emenda constitucional. ${ }^{8}$ Embora o $\S 3^{\circ}$ tenha limitado o alcance dos tratados

7 A questão da origem e evolução do princípio Ne bis in idem é detalhada nas páginas 131-133 da referida dissertação.

${ }^{8}$ Contrario sensu, o Supremo Tribunal Federal decidiu no julgamento do HC 72.131/RJ que o Pacto de São José da Costa Rica situa-se no mesmo nível de eficácia das leis ordinárias internas. 
internacionais de direitos humanos a aprovação "em cada casa do Congresso Nacional, em dois turnos, por três quintos dos votos dos respectivos membros", ressalta-se que tal norma tem aplicação apenas para os tratados e convenções sobre direitos humanos aprovados após a emenda constitucional 45/2004. Portanto, os tratados e convenções que já haviam sido incorporados ao direito interno, como o Pacto de São José da Costa Rica, não sofreram alteração:

De qualquer forma, haja vista sua natureza materialmente constitucional, dúvida não há de que, seja como garantia inscrita expressamente em tratado internacional de direitos humanos, incorporado ao direito interno com status equivalente à emenda constitucional, seja como garantia implícita, decorrente dos princípios adotados pela Constituição, o princípio ne bis in idem corresponde a uma garantia constitucional, que limita o ius persequendi, pelos mesmos fatos, a uma única oportunidade, cuja observância é obrigatória a todos os juízes e tribunais.(SABOYA, 2006, p. 148-149)

Tem estreita relação com a proteção da coisa julgada, disposta no art. 5o, XXXVI, da Constituição Federal (CF) e com o caráter excepcional da revisão criminal, que segundo previsto no Código de Processo Penal (CPP) nos arts. 621 e 626, parágrafo único, somente é cabível em face de sentença penal condenatória, para beneficiar o acusado, sendo vedado o agravamento da pena imposta pela decisão revista.

Conforme destacado por Giacomolli, a tríade relação entre coisa julgada, revisão criminal e ne bis in idem guardam relação direta com os fundamentos do Estado Constitucional: 
a proteção da coisa julgada insere-se no âmbito da proteção jurídica processual, um dos fundamentos do Estado Constitucional (...) conformador do devido processo. Por isso, nenhum ato poderá prejudicar a coisa julgada, seja ele do legislador, da cidadania ou do juiz. Sendo que a coisa julgada material opera somente em favor do acusado e não contra ele, preservando-se o estado de inocência. (...) Um dos efeitos da coisa julgada, operada com o trânsito em julgado da sentença, é impedir o processamento, o debate e nova declaração sobre o mesmo caso. (GIACOMOLLI, 2015, p. 332)

A partir da correlação entre a coisa julgada e a excepcionalidade da revisão criminal sustenta-se que a vedação ao bis in idem "serve como garantia ao cidadão de que não será julgado duplamente pelo mesmo fato e que o caso penal está encerrado temporalmente, somente modificável pro reo". (GIACOMOLLI, 2015, p. 333)

Saboya destaca que na sua concepção contemporânea o conteúdo do princípio ne bis in idem é aplicado nas vertentes, processual e material:

(a) $\mathrm{Na}$ vertente processual, corresponde à inadmissibilidade de múltipla persecução penal, simultânea ou sucessivamente, pelos mesmos fatos, vinculando-se à garantia constitucional da coisa julgada; e (b) na vertente material, diz respeito aos limites jurídico-constitucionais da acumulação de sanções penais e administrativas pelos mesmos fatos e mesmos fundamentos, ainda que impostas em ordens sancionadoras diversas. (SABOYA, 2006, p. 148-149)

Portanto, o seu alcance tornou-se mais abrangente, não se restringindo ao efeito processual, incorporando à dimensão substancial 
a proibição de se impor e executar mais de uma punição partindo-se dos mesmos fatos.

A construção do princípio ne bis in idem decorre da dignidade da pessoa humana e dos princípios basilares do Estado Democrático de Direito. Visa salvaguardar o indivíduo frente ao poder punitivo estabelecendo limitações. É nessa ótica que se preconiza o impedimento de sucessivas persecuções ou penalizações, sendo, em síntese, uma forma de limitação do poder punitivo estatal. (JAPIASSU, 2004, p. 95)

\section{A FUNÇÃO DOS PRINCÍPIOS NA EXECUÇÃO PENAL}

No âmbito da execução penal os princípios são também meios de limitação racional do poder punitivo executório do Estado sobre as pessoas condenadas. No entanto, verifica-se com frequência a subversão do seu conteúdo que é aplicado em prejuízo ao condenado. ${ }^{9}$

No sentido contrário, Rodrigo Roig parte de duas premissas fundamentais. A primeira é de que os princípios são escudos normativos de proteção do indivíduo, de forma que jamais podem ser evocados como fundamento para restringir direitos ou justificar maior rigor punitivo. A segunda premissa indica que a interpretação dos princípios em matéria de execução penal deve ser pro homine, devendo prevalecer sempre a solução que mais amplia o gozo e o exercício de um direito, liberdade ou garantia:

${ }^{9}$ Em se livro Execução Penal- teoria crítica Rodrigo Roig mostra outra situação, em que o princípio da individualização da pena é empregado em prejuízo ao condenado como fundamento para a exigência do Exame Criminológico (ROIG, 2017, p. 64). 
A aplicação e interpretação das normas em matéria de execução penal são permanentemente norteadas por princípios contidos na Constituição Federal, Código de Processo Penal, Código Penal, Lei de Execução Penal e nos Tratados e Convenções internacionais em matéria penal e de direitos humanos. Em uma visão penalconstitucional moderna, tais princípios não mais atuam como elementos meramente informadores ou programáticos, possuindo sim força normativa capaz de concretamente tutelar direitos fundamentais das pessoas condenadas. O processo de densificação dos princípios os transformou, afinal, em paradigmas substanciais (materiais) de validade das normas e atos administrativos. (ROIG, 2017, p. 31)

Conforme observado, tais premissas decorrem do preceito contido no art. 29, b, da Convenção Americana de Direitos Humanos que orienta a interpretação das normas de forma que "nenhuma disposição desta Convenção pode ser interpretada no sentido de limitar o gozo e exercício de qualquer direito ou liberdade que possam ser reconhecidos de acordo com as leis de qualquer dos Estados Partes ou de acordo com outra convenção em que seja parte um dos referidos Estados" e do Pacto Internacional sobre Direitos Civis e Políticos (PIDCP) que em seu art. 5o dispõe:

1. Nenhuma disposição do presente Pacto poderá ser interpretada no sentido de reconhecer a um Estado, grupo ou indivíduo qualquer direito de dedicar-se a quaisquer atividades ou praticar quaisquer atos que tenham por objetivo destruir os direitos ou liberdades reconhecidos no presente Pacto ou impor-lhe limitações mais amplas do que aquelas nele previstas; 2. Não se admitirá qualquer restrição ou suspensão dos direitos humanos fundamentais reconhecidos ou vigentes em 
qualquer Estado Parte do presente Pacto em virtude de leis, convenções, regulamentos ou costumes, sob pretexto de que o presente Pacto não os reconheça ou os reconheça em menor grau.

As prescrições normativas que dispõem sobre a impossibilidade de interpretação limitadora de direito ou liberdade assumem especial relevância em se tratando das pessoas encarceradas custodiadas pelo Estado, na medida em que, estabelecem limites imprescindíveis ao poder punitivo estatal.

\section{O PRINCÍPIO NE BIS IN IDEM E A SUA APLICAÇÃO SUBVERTIDA}

Em 06 de outubro de 2015 a $6{ }^{\text {a }}$ Câmara Criminal do Tribunal de Justiça do Estado de Minas Gerais proferiu decisão em que rejeitou embargos infringentes interpostos pela Defensoria Pública.

Trata-se de caso ocorrido no âmbito da execução penal em que o sentenciado possuía mais de uma condenação unificada e sobreveio decisão que concedeu o indulto em relação a dois crimes. O TJMG argumentou que o período de prisão referente aos crimes cujas penas foram indultadas, anterior à prática do crime cuja pena permanecia em execução, não poderia ser computado devendo ser retirado do atestado de pena do condenado o histórico de prisão referente a estes crimes. Na fundamentação da decisão justificou-se a negativa do pleito sob pena de configuração de "bis in idem contra o Estado".

Para o referido tribunal, admitindo-se o contrário "estar-se-ia computando um único período de cárcere como cumprimento de duas penas distintas" em uma tentativa de "driblar o instituto da soma das 
penas, computando cumulativamente o tempo cumprido em processos distintos". Argumentou-se que:

(...) não se pode admitir que o período em que o embargante permaneceu segregado preventivamente seja computado como período de pena cumprida, quando, simultaneamente, cumpria pena definitiva por outros processos, pois, como bem salientou a il. Desembargadora prolatora do voto vencedor, não se pode utilizar a pena cumprida duas vezes, sob pena de se incorrer em bis in idem contra o Estado, gerando ao réu um saldo de pena. (MINAS GERAIS, 2015) Grifo nosso.

Verifica-se que o princípio ne bis in idem foi empregado na fundamentação para extirpar dos registros de prisão do sentenciado, período em que esteve efetivamente segregado e que poderia ser contado como tempo de cumprimento de pena para fins de futuros benefícios da execução penal.

Contrariando a própria natureza dos princípios que, a partir do seu lastro constitucional, deveria exercer as funções de escudo para resguardar direitos e garantias fundamentais verifica-se que ele foi manipulado e subvertido para fazer prevalecer o exercício do poder de punir.

Ingerborg Maus na obra $O$ judiciário como superego da sociedade, ao discorrer sobre a destruição de direitos humanos e de soberania popular no século $\mathrm{XX}$, destacou a usurpação do recurso da argumentação do Direito pelo judiciário e o executivo para que a base social não mais controle os aparelhos estatais na defesa dos direitos de liberdade, mas, inversamente, a base social passe a ser controlada da perspectiva dos aparelhos estatais. Nesse sentido, “(...) todos os 
clássicos princípios jurídicos são convertidos em seu oposto." (MAUS, 2010, p. 184)

A reinvenção de direitos e garantias fundamentais a partir de sua flexibilização fazem com que a Constituição deixe de ser o critério por meio do qual os cidadãos podem controlar os aparelhos estatais. Reverte-se, assim, aquilo que seria a ratio essendi dos direitos de liberdade: direitos subjetivos como limitador do poder público, incluído o poder punitivo. (MAUS, 2010, p. 184)

A redução do objeto de discussão à ambivalência entre o direito público de punir e o direito privado à liberdade deixa de ter relevância quando se observa que os interesses do sentenciado "superam muito a esfera do "privado" situando-se na dimensão de direitos e garantias fundamentais (portanto, "público")". Isso é resultado da imposição, pelo Estado Democrático, de proteção do indivíduo face ao Estado. (LOPES JR., 2011, p. 11)

Dessa forma, a crítica se faz em duas vertentes. A primeira diz respeito à subversão principiológica propriamente dita a partir do desvirtuamento da função dos princípios, que originalmente são concebidos para tutela dos direitos fundamentais do cidadão dada a sua conexão direta com a normatividade constitucional. In casu, o que se viu foi a transmutação de um princípio para fazer prevalecer o poder punitivo do Estado em detrimento do direito fundamental à liberdade. A segunda vertente, que decorre da primeira, diz respeito ao conteúdo propriamente dito do que se pretende defender com tal inversão principiológica: a prevalência do onipotente poder de punir do Estado.

Reafirmar a subversão principiológica para sobrepor o poder punitivo estatal em detrimento de priorizar a incolumidade do direito fundamental à liberdade representa o retrocesso de se regastar as "teorias da supremacia especial do Estado em que os presos estariam em categoria com especial sujeição ao Estado, o que permitiria a 
flexibilização de princípios para redução ou supressão de direitos com fundamento na primazia do direito estatal". (ROIG, 2017, p. 586-587)

Tal retrocesso representa sobretudo verdadeira anulação paulatina do estado de direito, na medida que, o incompleto grau de observância dos princípios é paralelo a um defeito na sua realização. (ZAFFARONI, 2003, p. 200)

A partir do pensamento de Foucault ressalta-se que na construção jurídica da verdade, que se dá através do processo, o juiz produz a verdade e exerce o poder decisório de dar a última palavra sobre o conflito. Ocorre que, por vezes, este poder é exercido de maneira desarrazoada e arbitrária, como no caso em análise. A partir de interpretações distorcidas o juiz produz:

Discursos que podem matar, discursos de verdade e discursos que fazem rir. E os discursos de verdade que fazem rir e que têm o poder institucional de matar são, no fim das contas, numa sociedade como a nossa, discursos que merecem um pouco de atenção. (FOUCAULT, 2002, p.8)

São discursos que merecem atenção para que se perceba a sua real funcionalidade e para que se resista, não os aceitando enquanto verdade, na medida em que, inobstante a sua inexistência, no caso em análise subverte o conteúdo normativo e principiológico com vistas a prolongar o tempo de encarceramento do condenado no espaço de morte da prisão.

Revelam o fortíssimo laço do discurso do direito com o poder, que constitui suposta verdade com efeito dramaticamente real. (RUIZ, 2016, p. 646-647) Ocorre que: 
Un orden social diseñado a partir de una juridicidad que desconozca, reniegue o deje de lado las violaciones a los derechos humanos condena a sus integrantes a recorrer una y outra vez-lo sepan o no- el caminho del horror y de la represión. Impide la profundización y ampliación de práticas democráticas y mantiene vivos e insepultos a los desaparecidos y otorga a los victimarios un lugar aceptado para convivir con los demás. (RUIZ, 2016, p.651)

O direito somente faz sentido quando está a serviço do ser humano, constituindo espaços de vida! Quando ele é desvirtuado da sua principal finalidade, subvertido em instrumento do poder para ultrapassar limites e manter o condenado em um espaço de morte, não há nada de engraçado nisso.

\section{CONSIDERAÇÕES FINAIS}

O princípio ne bis in idem dispõe que ninguém será processado ou punido por fato pelo qual já tenha sido absolvido ou condenado por sentença transitada em julgado.

Trata-se de princípio geral de direito internacional, de caráter universal. Está previsto no art. 14.7 do Pacto Internacional de Direitos Civis e Políticos. Encontra previsão também no art. 4o do Protocolo 7ọ, adicional ao Convênio de Direitos Humanos; no art. 50 da Carta dos Direitos Fundamentais da União Europeia; na Convenção de Aplicação do Acordo de Schengen; no art. 50 da Carta dos Direitos Fundamentais 
da União Europeia e no art. 8.4 da Convenção Americana de Direitos Humanos.

O Brasil ratificou o Pacto Internacional dos Direitos Civis e Políticos e a Convenção Americana de Direitos Humanos. Conforme disposto no art. $5^{\circ}, \S^{\circ}$ e $\S 3^{\circ}$ da Constituição Federal de 1988 (CF) os tratados e convenções internacionais sobre direitos humanos são equivalentes à emenda constitucional.

Portanto, seja como garantia inscrita expressamente em tratado internacional de direitos humanos, incorporado ao direito interno com status equivalente à emenda constitucional; seja como garantia implícita, decorrente dos princípios adotados pela Constituição, o princípio ne bis in idem corresponde a uma garantia constitucional.

Consiste em garantia constitucional que, como tal, limita a interpretação tanto das normas processuais, conforme preconizado por Couture, como também as normas de natureza penal e de execução penal. Na sua concepção contemporânea o alcance do princípio ne bis in idem tornou-se mais abrangente, não se restringindo ao efeito processual, incorporando à dimensão substancial a proibição de se impor e executar mais de uma punição partindo-se dos mesmos fatos.

A construção do princípio ne bis in idem decorre da dignidade da pessoa humana e dos princípios básicos do Estado Democrático de Direito. Visa salvaguardar o indivíduo frente ao poder punitivo do Estado estabelecendo limitações. É nessa ótica que se preconiza o impedimento de sucessivas persecuções ou penalizações, decorrentes dos mesmos fatos.

Contrariando a própria natureza dos princípios que, a partir do seu lastro constitucional, deveria exercer função de escudo para resguardar direitos e garantias fundamentais verifica-se na decisão analisada que o princípio ne bis in idem foi manipulado e subvertido para fazer prevalecer o exercício do poder de punir. 
Evidencia-se que não é possível admitir que a sua interpretação restrinja direitos salvaguardados pelo próprio texto constitucional. Diante das possibilidades interpretativas, deve-se optar por aquela que mais atenta à salvaguarda dos direitos assegurados constitucionalmente, ampliando a proteção do indivíduo frente ao Estado.

A subversão principiológica para sobrepor o poder punitivo estatal em detrimento de priorizar a incolumidade do direito fundamental à liberdade representa um retrocesso e indica uma falha no desenvolvimento do próprio estado de direito.

A partir do destacado por Maus, verifica-se que a conversão dos princípios jurídicos em seu oposto consistiu no século XX e consiste ainda no século XXI na usurpação do recurso da argumentação do Direito pelo judiciário para que a base social não controle os aparelhos estatais na defesa dos direitos de liberdade, mas, inversamente, passe a ser controlada por eles.

Na decisão analisada a interpretação subvertida do princípio ne bis in idem em "bis in idem contra o Estado" distorce absolutamente a acepção do princípio jurídico. Constitui discurso de verdade que, se não fosse de morte, nos fariam rir. No entanto, conforme alertado por Foucault os discursos de verdade que fazem rir e que têm o poder de matar merecem atenção.

Atenção para que se perceba a sua real funcionalidade e para que se resista, não os aceitando enquanto verdade que, inobstante a sua inexistência, subverte o conteúdo normativo e principiológico com vistas a prolongar o tempo de encarceramento do condenado no espaço de morte da prisão.

O direito somente faz sentido quando está a serviço do ser humano, constituindo espaços de vida! Quando ele é desvirtuado da sua principal finalidade, subvertido em instrumento do poder para 
ultrapassar limites e manter o condenado em um espaço de morte, não há nada de engraçado nisso.

\section{REFERÊNCIAS}

CARVALHO, Salo de. Pena e Garantias. 3. ed. Rio de Janeiro: Lumen Juris, 2008.

COUTURE, Eduardo J. Estudios de derecho procesal civil: la constitución y el proceso civil. T.1. Buenos Aires: Ediar, Soc. Anón., Editores, 1948.

COUTURE, Eduardo J. Estudios de derecho procesal civil: el juez, las partes y el proceso. t.III. Buenos Aires: Ediar, 1950.

COUTURE, Eduardo J. Interpretação das leis processuais. Trad. Gilda Maciel Corrêa Meyer Russomano. 4. ed. Rio de Janeiro: Forense, 1994.

COUTURE, Eduardo J. La enseñanza de Chiovenda sobre interpretación de las leyes procesales. In: Revista de Derecho procesal. Año V, primera parte. Buenos Aires: Ediar, 1947, p. 514-527. 
FIX-ZAMUDIO, Héctor. Latinoamérica: constitución, proceso y derechos humnos. San Angel: Miguel Angel Possúa, 1998.

FOUCAULT, Michel. Os anormais. São Paulo: Martins Fontes, 2002.

GIACOMOLLI, Nereu José. O devido processo penal: abordagem conforme a Constituição Federal e o Pacto de São José da Costa Rica. 2. ed. São Paulo: Atlas, 2015.

JAPIASSU, Carlos Eduardo Adriano. O princípio do ne bis in idem no direito penal internacional. Revista da Faculdade de direito de Campos. Ano IV, nso 4 e 5 - 2003/2004.

LEAL, André Cordeiro. Instrumentalidade do processo em crise. Belo Horizonte: Mandamentos, Faculdade de Ciências Humanas/FUMEC, 2008.

LEAL, Rosemiro Pereira. Relativização inconstitucional da coisa julgada: temática processual e reflexões jurídicas. Belo Horizonte: Del Rey, 2005.

LEAL, Rosemiro Pereira. Teoria Geral do Processo: primeiros estudos. 13. ed. Belo Horizonte: Fórum, 2016. 
LOPES JR., Aury. Direito processual penal e sua conformidade constitucional. Vol. 1. 8. ed. Rio de Janeiro: Lumen Juris, 2011.

MAUS, Ingeborg. O judiciário como superego da sociedade. Trad. Geraldo de Carvalho e Gercélia Batista de Oliveira Mendes. Coleção Conexões Jurídicas. Rio de Janeiro: Lumen Juris, 2010.

MINAS GERAIS. Tribunal de Justiça. Embargos infringentes em agravo em execução penal 1.0481.13.005086-9/002. Relator: Luziene Barbosa Lima. 6a Câmara Criminal. Diário de Justiça eletrônico, Belo Horizonte, 19 out. 2015a. Disponível em: <http://www5.tjmg.jus.br/jurisprudencia/pesquisaNumeroCNJEspelh oAcordao.do;jsessionid=BE13D82AD8FB45B44A9B2298D0298B46.ju ri_node2? numeroRegistro $=1 \&$ totalLinhas $=1 \&$ linhasPorPagina $=10 \& n$ umeroUnico $=1.0481 .13 .005086$ 9\%2F002\&pesquisaNumeroCNJ=Pesquisar> Acesso em 07 abr. 2017.

ROIG, Rodrigo Duque Estrada. Execução Penal: teoria crítica. 3. ed. São Paulo: Saraiva, 2017.

RUIZ, Alicia E. C. Democracia y Orden Constitucional: el lugar de los jueces. In: CARVALHO, Diego de; CARVALHO, Gabriela; COSTA, Renata Almeida da; CARVALHO, Salo de (Organizadores). Para além do Direito Alternativo e do Garantismo Jurídico: ensaios em 
homenagem a Amilton Bueno de Carvalho. Rio de Janeiro: Lumen Juris, 2016.

SABOYA, Keity Mara Ferreira de Souza e. Ne bis in idem. Limites jurídico-constitucionais à persecução penal. Dissertação de Mestrado. Universidade Federal do Rio Grande do Norte. Disponível em: https://repositorio.ufrn.br/jspui/bitstream/123456789/.../1/keityMFS. pdf. Acesso em 30/04/2017.

ZAFFARONI, Eugênio Raúl et al. Direito penal brasileiro: teoria geral do direito penal. 2. ed. Rio de Janeiro: Revan, 2003, v. 1. 